\title{
Application of a Temperature-Dependent Load Prediction Method to a RUAG Six-Component Block-Type Balance
}

\author{
N. Ulbrich ${ }^{\dagger}$ \\ Jacobs Technology Inc., Moffett Field, California 94035 \\ C. Zimmermann $\ddagger$ \\ RUAG Aviation, 6032 Emmen, Switzerland
}

\begin{abstract}
Temperature-dependent data of a RUAG six-component block-type balance was analyzed to assess the accuracy of two load prediction methods for temperature-dependent balance data. The supplied data was prepared for the analysis by splitting it into calibration and check load data subsets. The first calibration data subset was obtained at a temperature of $294^{\circ} \mathrm{K}$. The second calibration data subset was obtained at a temperature of $315^{\circ} \mathrm{K}$. A subset of 38 points was extracted from the second data set and used as check loads so that the accuracy of the two load prediction methods could be tested. First, the Iterative Method in combination with an extended independent and dependent variable set was used for the balance load prediction. This approach fits electrical outputs as a function of loads and the temperature and, afterwards, constructs a load iteration scheme from the regression coefficients so that loads can be predicted from outputs and the temperature during a wind tunnel test. The Non-Iterative Method was also used for the load prediction. This alternate method can more easily be implemented in a data system as loads are directly fitted as a function of electrical outputs and the temperature. Analysis results for the axial force are only discussed in the paper as similar results were obtained for the other five load components. Results for both methods clearly show that the cross-product term constructed from either a primary gage load or a primary gage output and the temperature explains the majority of the temperature-dependent part of the predicted balance load. This term models the temperature-dependent nature of the gage sensitivity. Therefore, it is recommended to apply primary gage loadings at different temperatures during a balance calibration whenever temperature effects need to be described. These loadings will contain information about the temperature-dependent nature of the gage sensitivities that can be quantified by related cross-product terms in regression models of the data.
\end{abstract}

\section{Nomenclature}

$\begin{array}{ll}a_{\circ, k}, a_{1, k}, \ldots & =\text { regression coefficients of a transformed output (used by the Iterative Method) } \\ b_{\circ}, b_{1}, \ldots & =\text { regression coefficients of the axial force (used by the Non-Iterative Method) } \\ \mathbf{C}_{\mathbf{1}}^{-1} & =\text { first matrix that describes a load iteration equation (see Ref. [1], Eq. (6)) } \\ \mathbf{C}_{\mathbf{1}}^{-\mathbf{1}} \mathbf{C}_{\mathbf{2}} & =\text { second matrix that describes a load iteration equation (see Ref. [1], Eq. (6)) } \\ k & =\text { index of a transformed output } \\ \mathbf{F} & =\text { load vector of a strain-gage balance } \\ F_{x} & =\text { axial force of a strain-gage balance } \\ F_{y} & =\text { side force of a strain-gage balance } \\ F_{z} & =\text { normal force of a strain-gage balance }\end{array}$

$†$ Senior Aerodynamicist, NASA Ames Unitary Plan Wind Tunnels

$\ddagger$ Head Measurements/IT, Aerodynamics Department 


$\begin{array}{ll}M_{x} & =\text { rolling moment of a strain-gage balance } \\ M_{y} & =\text { pitching moment of a strain-gage balance } \\ M_{z} & =\text { yawing moment of a strain-gage balance } \\ \Delta T_{d} & =\text { temperature difference used as a dependent variable (Iterative Method only) } \\ \Delta T_{i} & =\text { temperature difference used as an independent variable } \\ U 1, U 2, \ldots, U 7 & =\text { measured balance outputs of a RUAG six-component block-type balance } \\ \mathbf{W} & =\text { vector with transformed outputs of a RUAG block-type balance } \\ W_{1} & =\text { electrical output of the axial force gage of a RUAG block-type balance } \\ W_{2} & =\text { transformed output of a RUAG block-type balance that is proportional to } F_{y} \\ W_{3} & =\text { transformed output of a RUAG block-type balance that is proportional to } F_{z} \\ W_{4} & =\text { transformed output of a RUAG block-type balance that is proportional to } M_{x} \\ W_{5} & =\text { transformed output of a RUAG block-type balance that is proportional to } M_{y} \\ W_{6} & \\ & =\text { axial force change caused by the temperature-dependent gage sensitivity shift } \\ \delta F_{x} & =\text { axial force residual (residual } \equiv \text { applied/observed value minus fitted value) } \\ \Delta F_{x} & =\text { data reduction matrix coefficient of a balance load component } \\ \xi & \end{array}$

\section{Introduction}

Recently a new approach was developed that predicts wind tunnel strain-gage balance loads in a situation when the load prediction accuracy is a function of the temperature of the balance (see Method 1 that is described in Ref. [1]). The new approach is a variation of the Iterative Method. It uses the difference between the balance temperature and a reference temperature as both an additional independent and dependent variable during the balance load prediction. This choice is the result of interpreting the uniform balance temperature as a "state" variable that supplements the description of both inputs and outputs of a strain-gage balance (see also the control volume analysis of "inputs" and "outputs" of a balance that is shown in Fig. 1 below).

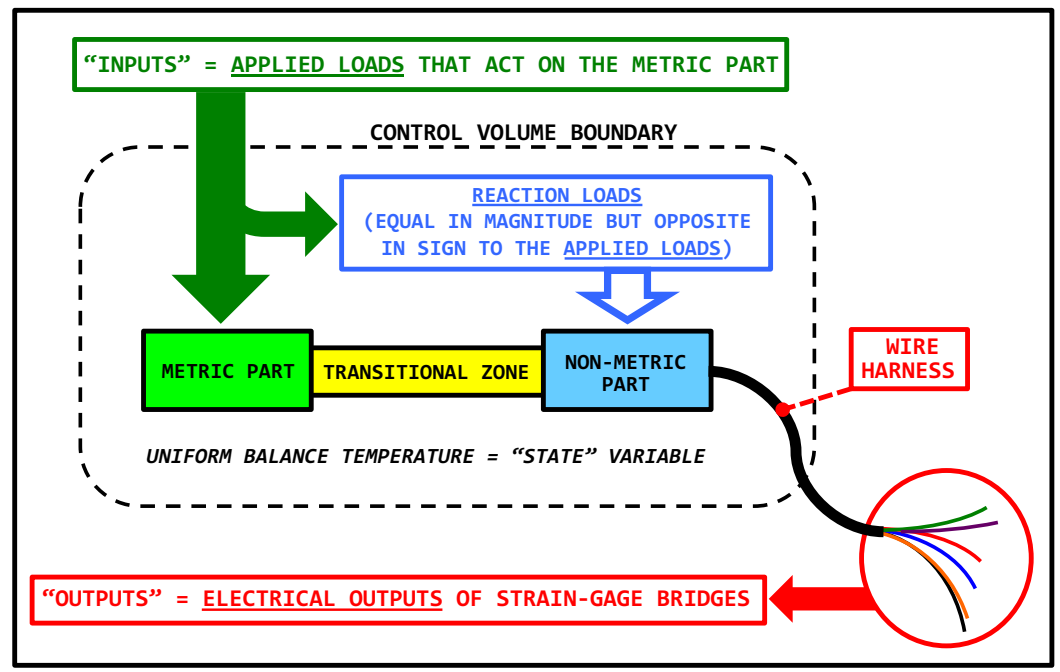

Fig. 1 Control volume analysis of the "inputs" and "outputs" of a strain-gage balance.

("transitional zone" $\equiv$ non-rigid part of the balance that has flexures \& gages)

The new approach applies a variation of the Iterative Method to the given temperature-dependent balance calibration data so that the traditional load iteration scheme for the load prediction can be constructed (see Ref. [1] and [2] for a description of this iteration scheme). The variation first fits the electrical outputs of the calibration data as a function of the loads and the temperature difference. Afterwards, the load iteration scheme is constructed from the regression analysis results so that loads can be predicted from the measured 
electrical outputs of the balance bridges and the balance temperature during the wind tunnel test.

It was rigorously demonstrated in Ref. [1] that it is critical to somehow quantify the temperaturedependent nature of the gage sensitivity in regression models of balance calibration data if accurate load predictions are to be achieved at different balance temperatures. It is possible to extend this important insight to the Non-Iterative Method so that this alternate load prediction method may also be used with temperature-dependent strain-gage balance data.

In principle, the Non-Iterative Method is much easier to apply to balance data than the Iterative Method as each load component is directly fitted as a function of the electrical outputs and no load iteration needs to be performed (see Ref. [3] for more details). In addition, it is the first author's experience that the load prediction accuracy of the Non-Iterative Method is as good as the load prediction accuracy of the Iterative Method as long as the chosen regression model of a load component (i) does not have hidden linear or near-linear dependencies and (ii) uses terms that are supported by the calibration data (see, e.g., Ref. [4] for a discussion of linear and near-linear dependency issues in regression models of experimental data). It was shown in Ref. [1] that a temperature-dependent sensitivity shift of a balance gage can be quantified by using a cross-product term in the regression model of an output that is constructed from (i) the related primary gage load and (ii) the temperature difference. Balances are often designed such that each output is more or less proportional to a single related load component. Then, a gage output can be approximated by the product of a constant and a related load component. Consequently, assuming that the Non-Iterative Method is applied, it is concluded that the temperature-dependent sensitivity shift of a balance gage must be quantified for this analysis choice by using a cross-product term in the regression model of a primary load component that is constructed from (i) the related primary gage output and (ii) the temperature difference.

Recently, highly accurate temperature-dependent calibration data of the RUAG 788-6A blocktype balance became available that was recorded at $294^{\circ} \mathrm{K} \& 315^{\circ} \mathrm{K}$. This balance belongs to a family of

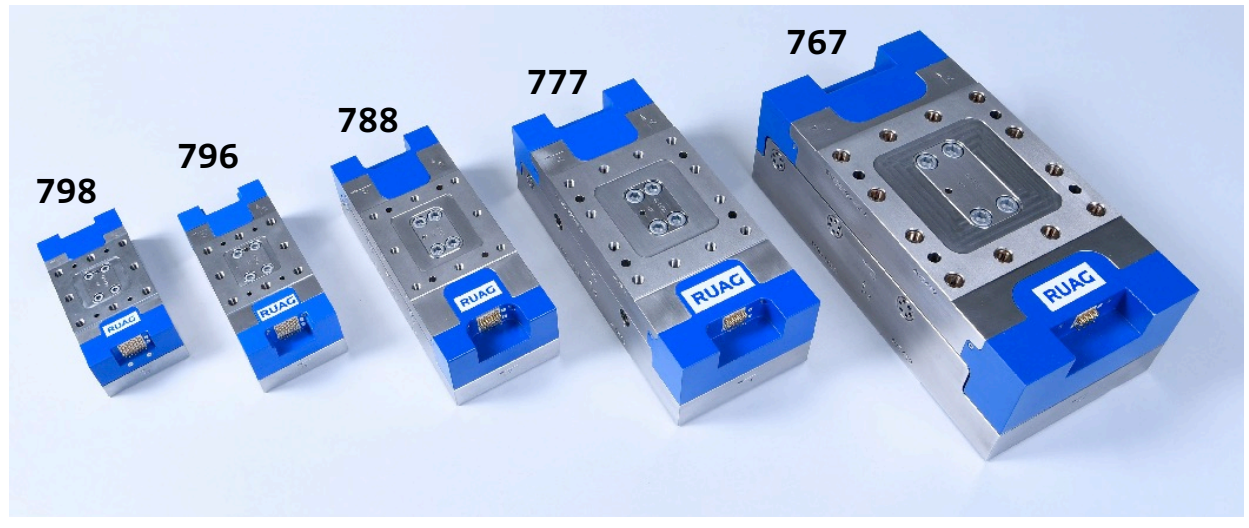

Fig. 2 Family of RUAG's six-component block-type balances (Models 798, 796, 788, 777, 767).

six block-type balances (five of the six balances are shown in Fig. 2 above). An initial evaluation of the calibration data indicated that it could be used to test the accuracy of the two proposed load prediction methods that are described above. These test results and the related analysis details are discussed in a later section of the paper. First, however, basic design features and the calibration of RUAG's block-type balances are reviewed so that it is easier for the reader to understand the final analysis results.

\section{Balance Description}

\section{A. Balance Design Features}

A family of 6-component block-type balances has been under development for many years at the Aerodynamics Department of RUAG (see Refs. [5], [6] for more details). These balances are designed to be used for a variety of wind tunnel test applications. For example, they may be used as internal balances when installed close to the model's aerodynamic center of pressure. Similarly, they may be used as external balances in vehicle aerodynamic testing when mounted on a turntable below the test section floor.

RUAG's family of block-type balances currently consists of six different balances that are scaled to 
meet different physical dimensions and load requirements. Their load capacities can be described by using either design loads or limit loads. The design loads are the maximum component loads assuming that all components are loaded simultaneously. Limit loads, on the other hand, are the maximum component loads assuming that only one component is loaded at a time. Table 1 below lists load capacities, i.e., the design loads, of the six block-type balances (capacities of the 788-6A balance are highlighted in boldface).

Table 1: Load capacities of RUAG's block-type balances ${ }^{\dagger}$.

\begin{tabular}{|c|c|c|c|c|c|c|}
\hline Type & $F_{x}, N$ & $F_{y}, N$ & $F_{z}, N$ & $M_{x}, N m$ & $M_{y}, N m$ & $M_{z}, N m$ \\
\hline \hline 798 & 500 & 400 & 2000 & 130 & 200 & 150 \\
\hline 796 & 1000 & 800 & 3500 & 350 & 350 & 350 \\
\hline $\mathbf{7 8 8}$ & $\mathbf{4 0 0 0}$ & $\mathbf{6 0 0}$ & $\mathbf{8 0 0 0}$ & $\mathbf{3 0 0}$ & $\mathbf{1 1 0 0}$ & $\mathbf{1 0 0 0}$ \\
\hline 776 & 1500 & 5500 & 5625 & 350 & 1300 & 650 \\
\hline 777 & 3000 & 4000 & 8500 & 1100 & 2500 & 1300 \\
\hline 767 & 13000 & 10000 & 30000 & 2300 & 3800 & 3100 \\
\hline
\end{tabular}

${ }^{\dagger}$ load capacity $\equiv$ maximum load of each load assuming a simultaneous loading of all components.

The balance itself consists of a non-metric base plate with seven trapezoidal beams that are connected by joint rods to their counterparts on the metric side. Each beam is instrumented with a strain-gage bridge that experiences an electrical signal change when the beam is elastically deformed. Figure 3 below shows details of the metric and non-metric part of a block-type balance after its blue protective covers are removed.

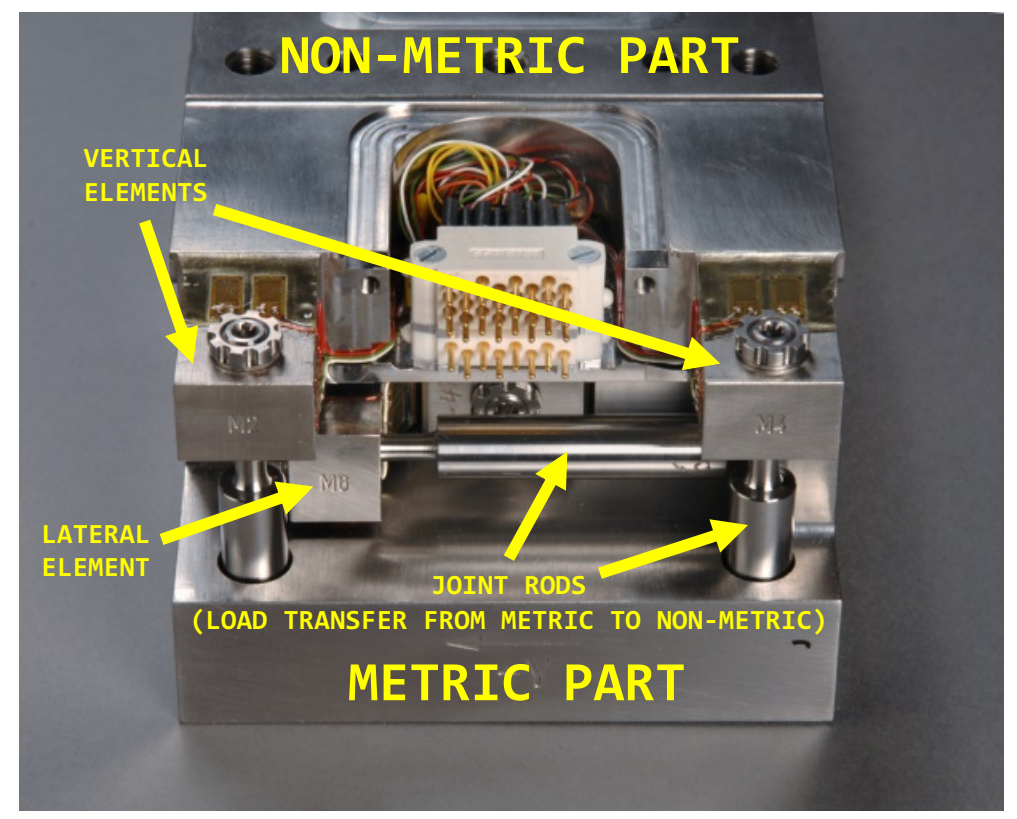

Fig. 3 Frontal view of RUAG's block-type balance after the removal of its blue protective cover; one lateral and two vertical measurement elements are shown.

RUAG's block-type balances measure six load components that are traditionally expressed in direct-read format $\left(F_{x}, F_{y}, F_{z}, M_{x}, M_{y}\right.$, and $\left.M_{z}\right)$. These loads are predicted using seven electrical output measurements as input $(U 1, U 2, \ldots, U 7)$. They can be transformed to six outputs (i.e., $\left.W_{1}, W_{2}, \ldots, W_{6}\right)$ so that (i) approximate linear relationships between one load component and one transformed output are established and (ii) the mathematical analysis of the balance data does not lead to an overdetermined linear system of equations. These output transformations for a RUAG block-type balance are defined as follows: 


$$
\begin{array}{ll}
W_{1}=+U 7 & \approx \text { proportional to } F_{x} \\
W_{2}=+U 5+U 6 & \approx \text { proportional to } F_{y} \\
W_{3}=+U 1+U 2+U 3+U 4 & \approx \text { proportional to } F_{z} \\
W_{4}=+U 1+U 2-U 3-U 4 & \approx \text { proportional to } M_{x} \\
W_{5}=-U 1+U 2-U 3+U 4 & \approx \text { proportional to } M_{y} \\
W_{6}=+U 5-U 6 & \approx \text { proportional to } M_{z}
\end{array}
$$

The output transformations make it possible to describe the entire calibration data set in a format that allows for the application of the Iterative Method. This approach can only be applied to balance data if the number of loads equals the number of outputs (see Ref. [7] for more details). The six related output/load pairs, i.e., $\left(W_{1}, F_{x}\right),\left(W_{2}, F_{y}\right),\left(W_{3}, F_{z}\right),\left(W_{4}, M_{x}\right),\left(W_{5}, M_{y}\right)$, and $\left(W_{6}, M_{z}\right)$, have the linear relationship that is beneficial during a regression analysis of strain-gage balance data. This characteristic can be illustrated, for example, by looking at the pairs $\left(W_{1}, F_{x}\right)$ and $\left(W_{5}, M_{y}\right)$. Figure 4 a below shows the transformed output $W_{1}$ plotted versus the related load $F_{x}$ after the tare corrected calibration data of the given temperaturedependent calibration data of RUAG's 788-6A balance is processed. It can be observed that the calibration

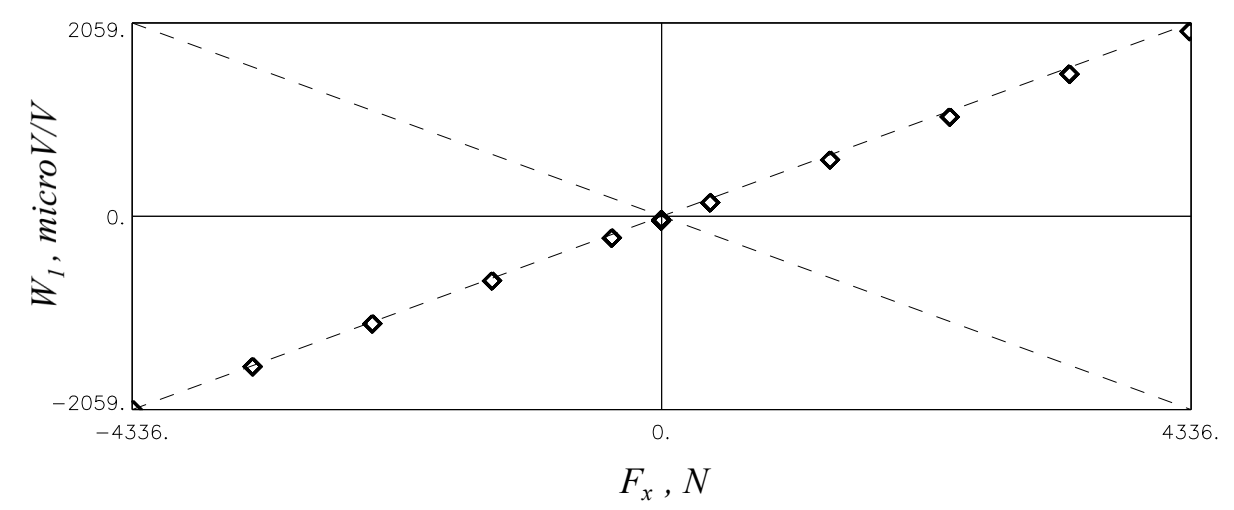

Fig. 4a Axial gage output of RUAG's 788-6A balance plotted versus the axial force for the combined calibration data that was recorded at $294^{\circ} \mathrm{K} \& 315^{\circ} \mathrm{K}$.

data depicted in Fig. 4a shows the desired linear relationship. This result is expected as (i) the transformed output $W_{1}$ equals the original electrical output $U 7$ of the axial force gage and (ii) $F_{x}$ is the axial force itself. Similarly, Fig. $4 \mathrm{~b}$ shows the fifth transformed output, i.e., $W_{5}$, plotted versus the related tare corrected pitching moment, i.e., $M_{y}$, after the temperature-dependent calibration data of RUAG's 788-6A balance is processed. Again, it can be observed that the calibration data depicted in Fig. 4b shows the desired linear

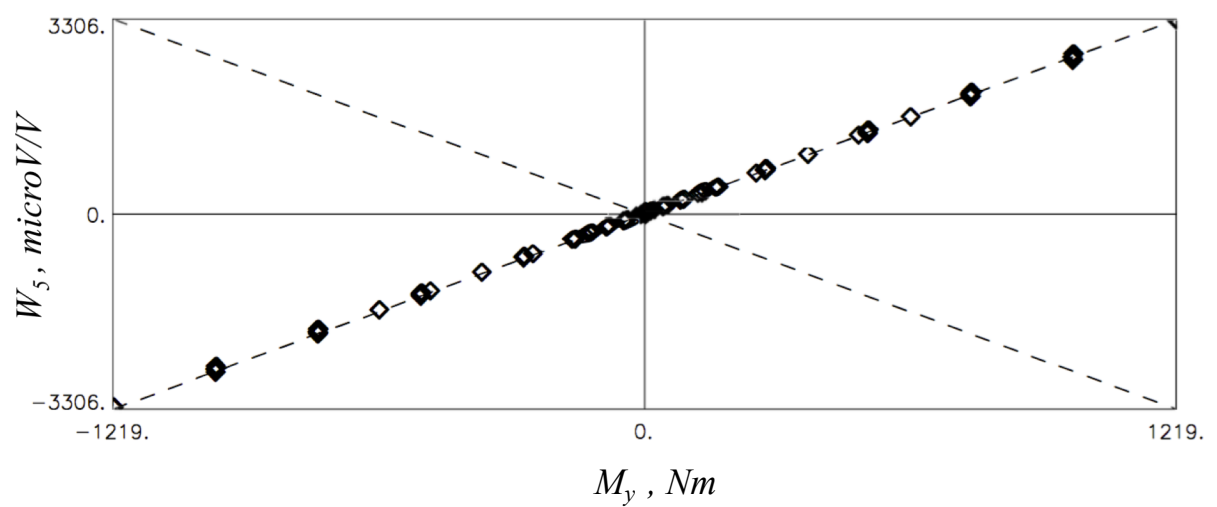

Fig. 4b Fifth transformed gage output of RUAG's 788-6A balance plotted versus the pitching moment for the combined calibration data that was recorded at $294^{\circ} \mathrm{K} \& 315^{\circ} \mathrm{K}$.

American Institute of Aeronautics and Astronautics 
relationship. However, this result is not intuitively obvious as (i) the transformed output $W_{5}$ is a linear combination of the four original outputs $U 1, U 2, U 3$, and $U 4$ and (ii) $M_{y}$ is the pitching moment of the balance.

\section{B. Temperature Effects}

RUAG's six-component block-type balances, similar to many balances that are used at the NASA Ames Unitary Plan Wind Tunnels, sometimes experience test situations when the temperature of the balance during a wind tunnel test differs from the temperature that the balance had during its calibration. This temperature difference could negatively influence the load prediction accuracy of the balance for a variety of reasons. For example, Youngs Modulus of a metal alloy is a function of the alloy's temperature (see Ref. [8]). Consequently, the elastic behavior of the balance may change when a significant temperature change occurs. In addition, residual imperfections of the temperature compensation of the gages themselves may negatively influence the load prediction. Finally, as indicated in Ref. [1], an unwanted gage sensitivity shift may occur that could negatively influence the load prediction accuracy of the balance. Therefore, RUAG decided to perform a temperature calibration of its 788-6A balance at two temperature levels to better understand and characterize the physical behavior of the balance at different temperatures. Basic elements of this calibration are described in the next section of the paper.

\section{Balance Calibration}

RUAG performs manual calibrations of its family of six-component block-type balances by exclusively using dead weights. This approach has the advantage that the direction of the load vector can accurately be determined by using highly sensitive spirit levels for the alignment of the calibration body relative to the direction of the gravitational acceleration. It also means that a maximum of three load components, i.e., one force and two moments, can be applied simultaneously. Figure 5 below shows, for example, the typical calibration hardware setup in RUAG's balance calibration laboratory.

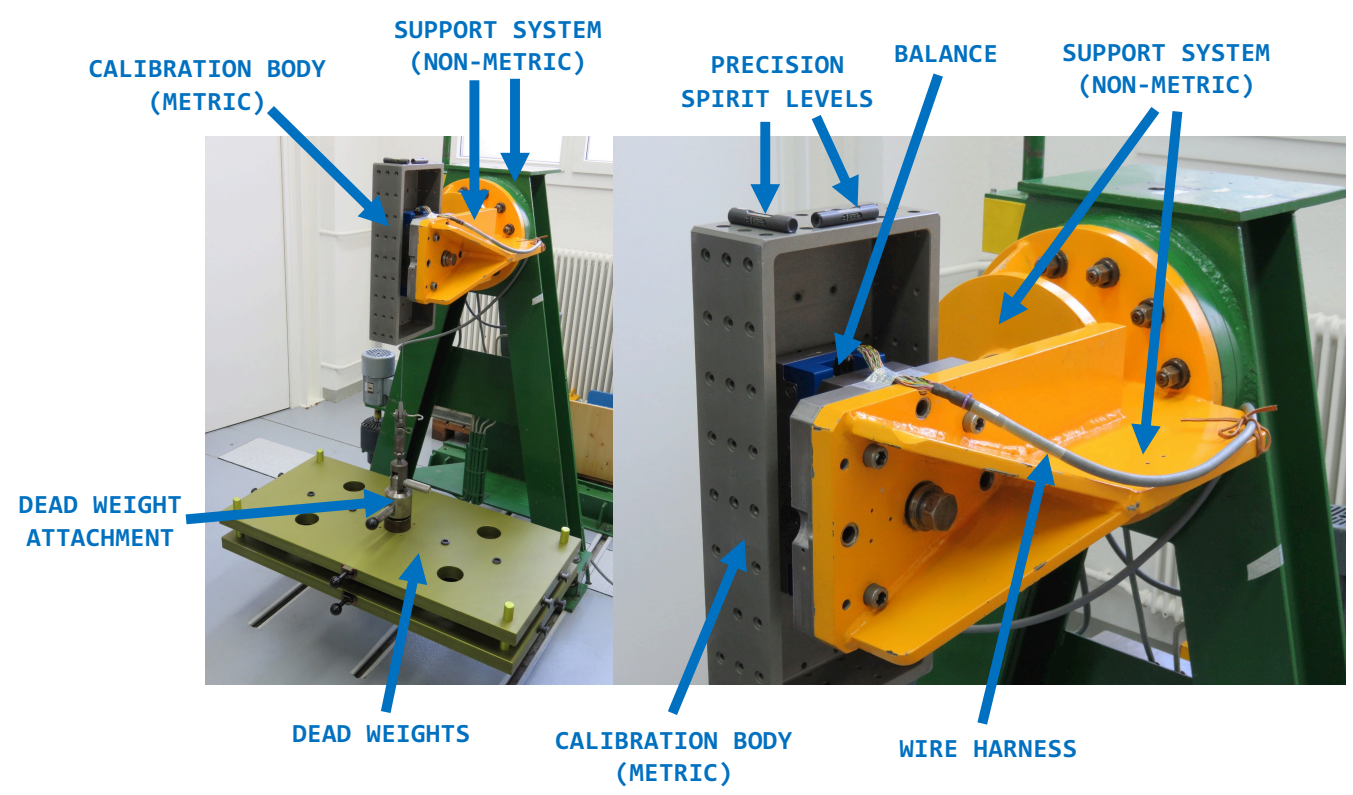

Fig. 5 RUAG's manual load rig for the calibration of block-type balances.

RUAG's manual balance calibration system uses HBM DMP40 data acquisition hardware, Wyler precision spirit levels, and dead weights that are calibrated using IOLM standards (see Ref. [9]). A typical calibration load schedule has approximately 450 data points that consists of one-, two-, and three-component loadings.

The calibration of the 788-6A balance was performed at two different temperature levels: $294^{\circ} \mathrm{K}\left(21^{\circ} \mathrm{C}\right.$ or $\left.70^{\circ} \mathrm{F}\right)$ and $315^{\circ} \mathrm{K}\left(42^{\circ} \mathrm{C}\right.$ or $\left.107^{\circ} \mathrm{F}\right)$. No component part of RUAG's balance calibration system had to 
be thermally insulated during the calibration as the entire calibration room was brought up to calibration temperature. A total number of 406 one-, two-, and three-component loadings was applied at the baseline temperature of $294^{\circ} \mathrm{K}$. A reduced number of 92 one- and two-component loadings was applied at the elevated temperature of $315^{\circ} \mathrm{K}$. It was decided to split the loadings obtained at $315^{\circ} \mathrm{K}$ into two subsets of 54 and 38 data points each so that both calibration and check load points would be available for the data analysis. Table 2 below summarizes basic characteristics of the supplied calibration data of the $788-6 \mathrm{~A}$ block-type balance.

Table 2: Calibration and check load data sets of RUAG's 788-6A block-type balance.

\begin{tabular}{|c|c|c|c|}
\hline & Temperature & Number of Points & Comments \\
\hline \hline Set 1 & $294^{\circ} \mathrm{K}$ & 406 & one-, two-, and three-component calibration loads \\
\hline Set 2 & $315^{\circ} \mathrm{K}$ & 54 & one- and two-component calibration loads \\
\hline Set 3 & $315^{\circ} \mathrm{K}$ & 38 & one- and two-component check loads \\
\hline
\end{tabular}

The analysis of the temperature-dependent calibration data of RUAG's 788-6A balance is described in the next section of the paper. The analysis illustrates in detail how balance loads may be predicted from measured outputs and the temperature difference. First, basic assumptions associated with the two chosen load prediction methods, i.e., with the Iterative Method and the Non-Iterative Method, are reviewed. Then, the methods are applied to the calibration and check load data.

\section{Data Analysis}

\section{A. General Remarks}

Two different methods are used in the aerospace testing community to predict balance loads from measured strain-gage outputs during a wind tunnel test. They are called the Iterative Method and the Non-Iterative Method (see Ref. [3] for more detail). Both methods fit balance calibration data in the least squares sense and use the result of the analysis for the prediction of balance loads from measured outputs.

The two load prediction methods differ in the selection of the independent and dependent variables that are used for the least squares fit of the balance calibration data. The Iterative Method treats balance loads as independent variables and gage outputs as dependent variables during the regression analysis. In other words, the method fits gage outputs as a function of balance loads. Therefore, the Iterative Method needs to construct a load iteration scheme from the result of the regression analysis so that loads can be predicted from measured outputs during a wind tunnel test. The Non-Iterative Method, on the other hand, treats balance loads as dependent variables and gage outputs as independent variables during the regression analysis. The method directly fits loads as a function of measured gage outputs. Consequently, the NonIterative Method is more easily implemented and applied than the Iterative Method as no iteration is needed to predict loads from gage outputs during a wind tunnel test. Table 3 below summarizes the variable choices for the two balance load prediction methods.

Table 3: Variable choices for the analysis of strain-gage balance calibration data.

\begin{tabular}{|c|c|c|}
\hline & Iterative Method & Non-Iterative Method \\
\hline \hline Independent Variables & loads (forces \& moments) & strain-gage outputs \\
\hline Dependent Variables & strain-gage outputs & loads (forces \& moments) \\
\hline
\end{tabular}

It is helpful for a better understanding of the two load prediction methods to describe the "load state" of the balance by using the control volume approach that is shown in Fig. 1 (see also Ref. [7]). The input variables of the control volume are the "loads" that act on the metric part of the balance. They can be described in vector format as follows: 


$$
\text { Load Vector } \Longrightarrow \quad \mathbf{F}=\left[\begin{array}{c}
F_{x} \\
F_{y} \\
F_{z} \\
M_{x} \\
M_{y} \\
M_{z}
\end{array}\right]
$$

The symbols $F_{x}, F_{y}, \ldots, M_{z}$ are the six load components of a balance assuming that they are described in direct-read format. The output variables of the control volume are the measured electrical outputs (or output combinations) of the strain-gage bridges that "exit" the control volume through the wire harness. These output variables can be described in vector format as follows:

$$
\text { Output Vector } \Longrightarrow \quad \mathbf{W}=\left[\begin{array}{l}
W_{1} \\
W_{2} \\
W_{3} \\
W_{4} \\
W_{5} \\
W_{6}
\end{array}\right]
$$

The symbols $W_{1}, W_{2}, \ldots, W_{6}$ are the six bridge outputs of the balance (they equal the transformed outputs given in Eqs. $(1 a)$ to $(1 f)$ if data of one of RUAG's block-type balance is analyzed). These six outputs directly respond to the six loads that act on the metric part of the balance.

Now, let us assume that (i) the load vectors define a "load space" and (ii) the output vectors define an "output space." Each load vector identifies a point in the six-dimensional "load space" that describes a "load state" of the balance. Similarly, each output vector identifies a point in the six-dimensional "output space" that describes a "load state" of the balance. Consequently, the load prediction will only work reliably if a load vector describing a specific "load state" of the balance in the "load space" is "uniquely" mapped to an output vector that describes the same "load state" in the "output space" (and vice versa). In other words, a reliable load prediction method establishes a "unique" mapping between the load and output spaces such that two different descriptions of one specific "load state" of the balance get connected.

Figure 6a below shows the situation from the viewpoint of the Iterative Method. In this case, the regression analysis defines a mapping from the load space to the output space (Step 1). Then, an iteration process is defined from the regression analysis results that "reverses" the mapping so that loads can be

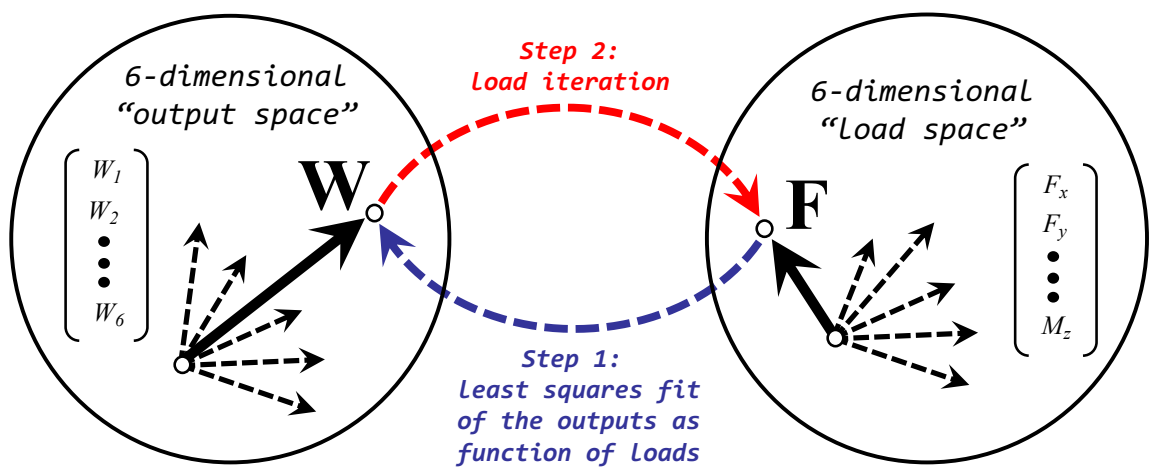

Fig. 6a Two step load prediction process of the Iterative Method.

predicted from outputs during a wind tunnel test (Step 2). Figure 6b shows, on the other hand, the situation for the Non-Iterative Method. Now, the prediction is much simpler as only a single step is required to obtain loads from outputs. The regression analysis directly defines a mapping from the output space to the load space that can be used to predict loads from the outputs during a wind tunnel test. Both the components 


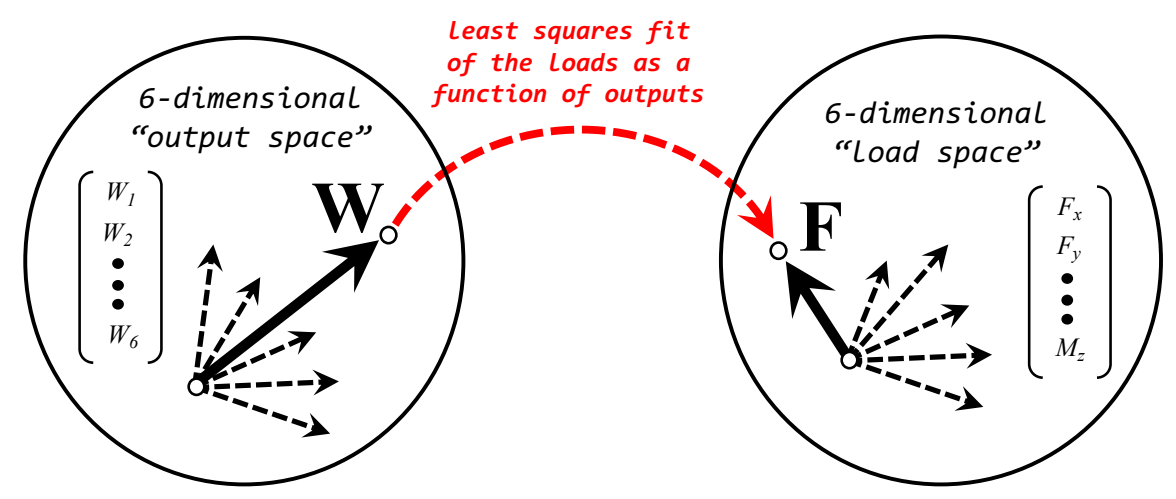

Fig. 6b Single step load prediction process of the Non-Iterative Method.

of the load vector and the components of the output vector have uncertainties associated with them. In particular, the uncertainty of the load vector will depend on the mathematical mapping between the load and output spaces whenever a tare load iteration is needed so that all loads are referenced to zero absolute load. However, the total "information" contained in a given calibration data set about the true physical behavior of the balance must be independent of the chosen load prediction method if small differences in the predicted tare loads are ignored. This fundamental conclusion is confirmed by the first author's past experience. He consistently observed that the load prediction accuracy of the Iterative Method is as good as the load prediction accuracy of the Non-Iterative Method as long as (i) similar regression models of the calibration data are used to construct the mapping from load space to output space (or vice versa) and (ii) the terms of the regression models do not have linear or massive near-linear dependencies.

It will be demonstrated in the next section of the paper how the Iterative Method may be applied to the temperature-dependent calibration data of RUAG's 788-6A balance. Afterwards, the application of the Non-Iterative Method to the same calibration data will be discussed.

\section{B. Iterative Method}

It is useful to first analyze the calibration data acquired at $294^{\circ} \mathrm{K}$ in order to better understand the impact of temperature effects on the balance load prediction (see Set 1 in Table 2 above). This data was processed by using the variation of the Iterative Method, i.e., Method 1 of Ref. [1], in combination with NASA's BALFIT software (see Ref. [10]). The calibration data consisted of 406 points. Table 4 below shows the regression model terms of the six transformed outputs that BALFIT used for the data analysis. Only seven of fifteen possible cross-product terms are used because the remaining eight load combinations were either not explicitly applied during the calibration or related load magnitudes were too small. No temperature-dependent terms were needed as the temperature of all data points of Set 1 was $294^{\circ} \mathrm{K}$.

Table 4: Supported regression model terms of the outputs that were recorded at $294^{\circ} \mathrm{K}$.

\begin{tabular}{|c|c|}
\hline Type & Iterative Method $\Longrightarrow$ List of Regression Model Terms for $W_{1}, W_{2}, \ldots, W_{6}$ \\
\hline \hline constant $(1)$ & Intercept \\
\hline linear $(6)$ & $F_{x}, F_{y}, F_{z}, M_{x}, M_{y}, M_{z}$ \\
\hline quadratic $(6)$ & $F_{x}^{2}, F_{y}^{2}, F_{z}^{2}, M_{x}^{2}, M_{y}^{2}, M_{z}^{2}$ \\
\hline cross-product $(7)$ & $\left(F_{x} \cdot M_{z}\right),\left(F_{y} \cdot M_{x}\right),\left(F_{y} \cdot M_{z}\right),\left(F_{z} \cdot M_{x}\right),\left(F_{z} \cdot M_{y}\right),\left(M_{x} \cdot M_{y}\right),\left(M_{x} \cdot M_{z}\right)$ \\
\hline
\end{tabular}

The regression model of each one of the six transformed gage outputs of RUAG's calibration data has the following general form: 


$$
\begin{aligned}
W_{k}=a_{\circ, k} & +\underbrace{a_{1, k} \cdot F_{x}+a_{2, k} \cdot F_{y}+\ldots+a_{6, k} \cdot M_{z}}_{\text {linear terms }}+\underbrace{a_{7, k} \cdot F_{x}^{2}+\ldots+a_{12, k} \cdot M_{z}^{2}}_{\text {quadratic terms }} \\
& +\underbrace{a_{13, k} \cdot F_{x} \cdot M_{z}+a_{14, k} \cdot F_{y} \cdot M_{x}+\ldots+a_{19, k} \cdot M_{x} \cdot M_{z}}_{\text {cross-product terms }}
\end{aligned}
$$

The BALFIT software fitted the six outputs using (i) the regression model defined in Eq. (4) and (ii) the calibration data as input. Then, a data reduction matrix was generated from the regression coefficients that defines the load iteration scheme. Figure 7a shows, for example, the final load residuals of the axial force, i.e., the difference between tare corrected and predicted axial force, of the calibration data at $294^{\circ} \mathrm{K}$ plotted versus the tare corrected axial force itself (results for the other five load components looked similar).

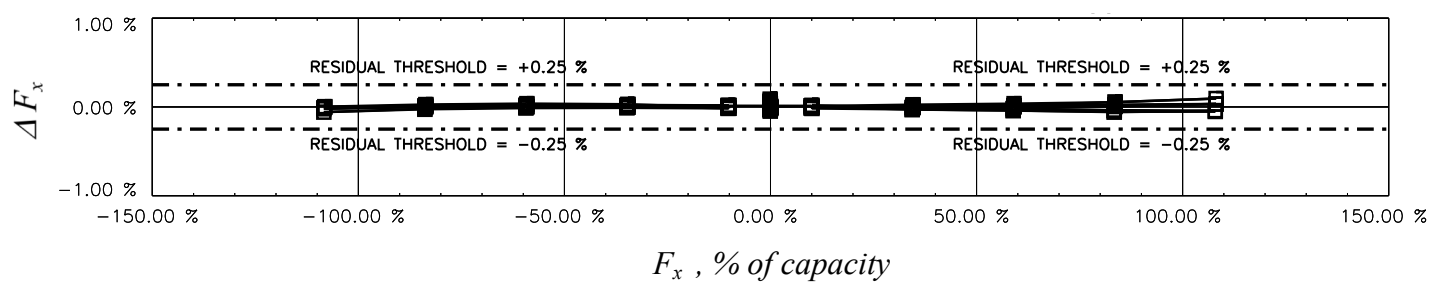

Fig. 7a Calibration load residuals of the axial force for the data that was recorded at $294^{\circ} \mathrm{K}$.

Overall, results of the load prediction are very good as the residuals of all 406 calibration points are within the $\pm 0.25 \%$ load capacity threshold that is traditionally used in aerospace testing for the assessment of balance load residuals.

In the next step, the data reduction matrix obtained from the calibration data at $294^{\circ} \mathrm{K}$ was applied to the 38 check load points that were recorded at $315^{\circ} \mathrm{K}$. Figure $7 \mathrm{~b}$ shows resulting check load residuals of the axial force plotted versus the tare corrected axial force of each check load point.

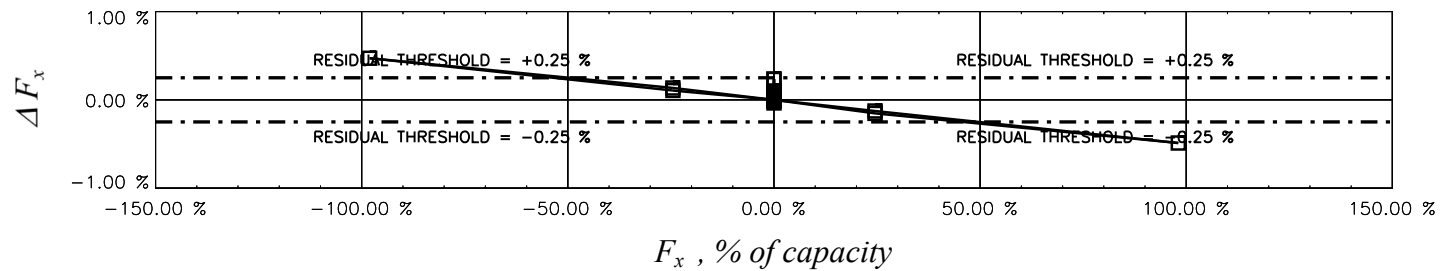

Fig. $7 \mathbf{b}$ Check load residuals of the axial force if the matrix obtained from the data at $294^{\circ} \mathrm{K}$ is used to process the outputs that were recorded at $315^{\circ} \mathrm{K}$.

This time, an unwanted "slope" is clearly visible in the check load residual plot. This observation indicates that the primary sensitivity of the axial force gage of the balance changed when the balance was heated to $315^{\circ} \mathrm{K}$. Therefore, it will be necessary to analyze the original calibration data using the new approach for temperature-dependent balance data that is discussed in Ref. [1] as the data reduction matrix obtained exclusively from the $294^{\circ} \mathrm{K}$ data does not correctly process outputs that were recorded at the elevated balance temperature of $315^{\circ} \mathrm{K}$.

Now, in order to obtain a temperature-dependent data reduction matrix for the processing of the check load data at $315^{\circ} \mathrm{K}$, the new approach described in Ref. [1] was applied to the combined calibration data that consisted of (i) the 406 data points at $294^{\circ} \mathrm{K}$ and (ii) the 54 data points at $315^{\circ} \mathrm{K}$ (see also Set 1 and Set 2 in Table 2). Table 5 below shows the regression model terms of the six transformed gage outputs that were used for this part of the analysis. Again, only seven of fifteen temperature-independent cross-product terms are used because the remaining eight load combinations were either not explicitly applied during the calibration or related load magnitudes were too small. This time, seven temperature-dependent regression model terms are included in the analysis of the six gage outputs as the combined calibration data was either recorded at $294^{\circ} \mathrm{K}$ or at $315^{\circ} \mathrm{K}$. 
Table 5: Supported regression model terms of the outputs that were recorded at $294^{\circ} \mathrm{K} \& 315^{\circ} \mathrm{K}$.

\begin{tabular}{|c|c|}
\hline Type & Iterative Method $\Longrightarrow$ List of Regression Model Terms for $W_{1}, W_{2}, \ldots, W_{6}$ \\
\hline \hline constant $(1)$ & Intercept \\
\hline linear $(6)$ & $F_{x}, F_{y}, F_{z}, M_{x}, M_{y}, M_{z}$ \\
\hline quadratic $(6)$ & $F_{x}^{2}, F_{y}^{2}, F_{z}^{2}, M_{x}^{2}, M_{y}^{2}, M_{z}^{2}$ \\
\hline cross-product $(7)$ & $\left(F_{x} \cdot M_{z}\right),\left(F_{y} \cdot M_{x}\right),\left(F_{y} \cdot M_{z}\right),\left(F_{z} \cdot M_{x}\right),\left(F_{z} \cdot M_{y}\right),\left(M_{x} \cdot M_{y}\right),\left(M_{x} \cdot M_{z}\right)$ \\
\hline temperature $(7)$ & $\Delta T_{i},\left(F_{x} \cdot \Delta T_{i}\right),\left(F_{y} \cdot \Delta T_{i}\right),\left(F_{z} \cdot \Delta T_{i}\right),\left(M_{x} \cdot \Delta T_{i}\right),\left(M_{y} \cdot \Delta T_{i}\right),\left(M_{z} \cdot \Delta T_{i}\right)$ \\
\hline
\end{tabular}

The BALFIT software's analysis of the combined calibration data showed that a total of 27 regression model terms for each transformed output were supported (intercept, seven linear terms, six quadratic terms, and thirteen cross-product terms). The corresponding regression model of a transformed output has the following form:

$$
\begin{aligned}
W_{k}=a_{\circ, k} & +\underbrace{a_{1, k} \cdot F_{x}+a_{2, k} \cdot F_{y}+\ldots+a_{6, k} \cdot M_{z}+a_{7, k} \cdot \Delta T_{i}}_{\text {linear terms }} \\
& +\underbrace{a_{8, k} \cdot F_{x}^{2}+a_{9, k} \cdot F_{y}^{2}+\ldots+a_{13, k} \cdot M_{z}^{2}}_{\text {quadratic terms }} \\
& +\underbrace{a_{14, k} \cdot F_{x} \cdot M_{z}+a_{15, k} \cdot F_{y} \cdot M_{x}+\ldots+a_{20, k} \cdot M_{x} \cdot M_{z}}_{\text {cross-product terms }} \\
& +\underbrace{a_{21, k} \cdot F_{x} \cdot \Delta T_{i}+a_{22, k} \cdot F_{y} \cdot \Delta T_{i}+\ldots+a_{26, k} \cdot M_{z} \cdot \Delta T_{i}}_{\text {temperature-dependent cross-product terms }}
\end{aligned}
$$

In the next step, a data reduction matrix was generated from the combined calibration data so that a temperature-dependent load iteration scheme for the load prediction could be defined. Figure 8a shows, for example, the load residuals of the axial force of the combined calibration data plotted versus the tare corrected axial force itself.

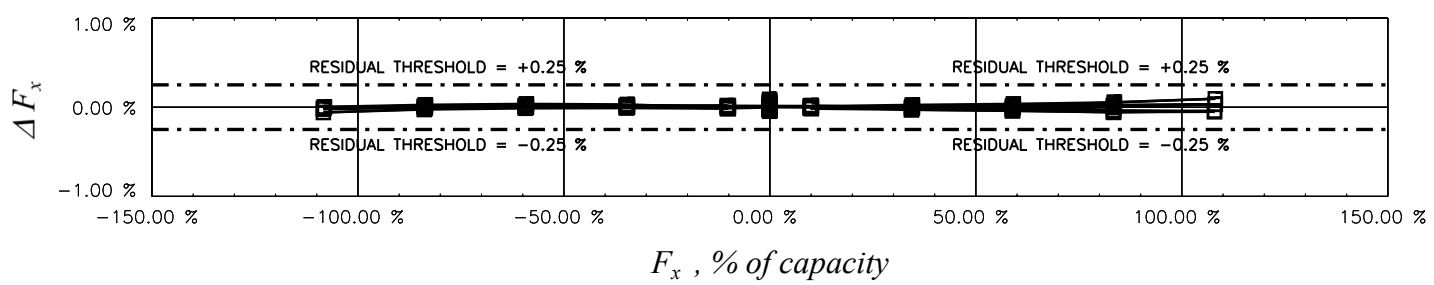

Fig. 8a Calibration load residuals of the axial force for the data that was recorded at $294^{\circ} \mathrm{K} \& 315^{\circ} \mathrm{K}$.

Again, results of the load prediction are very good as the residuals of all 460 calibration points are within the $\pm 0.25 \%$ load capacity threshold that is used in aerospace testing for the assessment of balance load residuals (results for the other five load components were similar). Then, the data reduction matrix obtained from the combined calibration was applied to the 38 check load points that were recorded at $315^{\circ} \mathrm{K}$. Figure $8 \mathrm{~b}$ below shows the resulting residuals of the axial force for the check load data at $315^{\circ} \mathrm{K}$ plotted versus the tare corrected axial force of each check load point. 


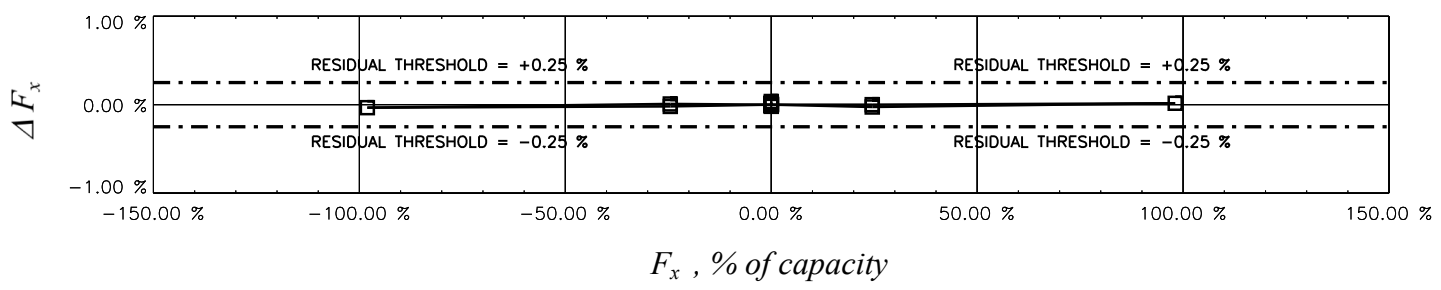

Fig. $8 \mathrm{~b}$ Check load residuals of the axial force if the matrix obtained from the combined data at $294^{\circ} \mathrm{K} \mathrm{\&} 315^{\circ} \mathrm{K}$ is used to process outputs that were recorded at $315^{\circ} \mathrm{K}$.

This time, the prediction of the check load data at $315^{\circ} \mathrm{K}$ meets accuracy requirements as (i) the residuals of all 38 check load points are well within the $\pm 0.25 \%$ load capacity threshold and (ii) the "slope" seen earlier in Fig. 7b has disappeared.

Contributions of the individual regression model terms of the combined calibration data can be examined in more detail in order to identify the term that is primarily responsible for the correct characterization of the temperature-dependent nature of the gage sensitivity. For simplicity, it was decided to only focus on the subset of data reduction matrix coefficients that are associated with the prediction of the axial force $F_{x}$. They are listed in Table 6 below assuming that the load iteration equation defined in Eq. (6) of Ref. [1] is applied. Two matrices, i.e., $\mathbf{C}_{\mathbf{1}}^{-\mathbf{1}}$ and $\mathbf{C}_{\mathbf{1}}^{-\mathbf{1}} \mathbf{C}_{\mathbf{2}}$, are used in Eq. (6) of Ref. [1] in order to describe the load

Table 6: Subset of data reduction matrix coefficients needed for the prediction of the axial force.

\begin{tabular}{|c|c|}
\hline Math Term $\Longrightarrow$ Coefficient, Unit & Math Term $\Longrightarrow$ Coefficient, Unit \\
\hline \hline$W_{1} \Longrightarrow+2.149202 \mathrm{E}+00[N /(\mu V / V)]$ & $F_{y} \cdot M_{x} \Longrightarrow+5.791194 \mathrm{E}-08[1 /(N m)]$ \\
\hline$W_{2} \Longrightarrow+3.163396 \mathrm{E}-03[N /(\mu V / V)]$ & $F_{y} \cdot M_{z} \Longrightarrow-6.669799 \mathrm{E}-07[1 /(N m)]$ \\
\hline$W_{3} \Longrightarrow-5.648385 \mathrm{E}-04[N /(\mu V / V)]$ & $F_{z} \cdot M_{x} \Longrightarrow+8.121756 \mathrm{E}-08[1 /(N m)]$ \\
\hline$W_{4} \Longrightarrow+3.814165 \mathrm{E}-05[N /(\mu V / V)]$ & $F_{z} \cdot M_{y} \Longrightarrow+1.149711 \mathrm{E}-06[1 /(N m)]$ \\
\hline$W_{5} \Longrightarrow+6.565511 \mathrm{E}-03[N /(\mu V / V)]$ & $M_{x} \cdot M_{y} \Longrightarrow-1.460893 \mathrm{E}-06\left[1 /\left(N m^{2}\right)\right]$ \\
\hline$W_{6} \Longrightarrow+1.038078 \mathrm{E}-03[N /(\mu V / V)]$ & $M_{x} \cdot M_{z} \Longrightarrow-3.030133 \mathrm{E}-05\left[1 /\left(N m^{2}\right)\right]$ \\
\hline$\Delta T_{d} \Longrightarrow-2.008885 \mathrm{E}-02\left[N /{ }^{\circ} K\right]$ & $F_{x} \cdot \Delta T_{i} \Longrightarrow+\mathbf{2 . 4 5 2 6 9 2} \mathrm{E}-\mathbf{0 4}\left[1 /{ }^{\circ} \mathrm{K}\right]$ \\
\hline$F_{x}^{2} \Longrightarrow-6.651383 \mathrm{E}-08[1 / N]$ & $F_{y} \cdot \Delta T_{i} \Longrightarrow+2.995279 \mathrm{E}-05\left[1 /{ }^{\circ} \mathrm{K}\right]$ \\
\hline$F_{y}^{2} \Longrightarrow-3.482894 \mathrm{E}-09[1 / N]$ & $F_{z} \cdot \Delta T_{i} \Longrightarrow+6.236862 \mathrm{E}-05\left[1 /{ }^{\circ} \mathrm{K}\right]$ \\
\hline$F_{z}^{2} \Longrightarrow+2.231772 \mathrm{E}-08[1 / N]$ & $M_{x} \cdot \Delta T_{i} \Longrightarrow+1.110948 \mathrm{E}-04\left[1 /\left(m^{\circ} \mathrm{K}\right)\right]$ \\
\hline$M_{x}^{2} \Longrightarrow+1.503580 \mathrm{E}-07\left[1 /\left(N m^{2}\right)\right]$ & $M_{y} \cdot \Delta T_{i} \Longrightarrow-5.382800 \mathrm{E}-05\left[1 /\left(m^{\circ} \mathrm{K}\right)\right]$ \\
\hline$M_{y}^{2} \Longrightarrow-2.097766 \mathrm{E}-08\left[1 /\left(N m^{2}\right)\right]$ & $M_{z} \cdot \Delta T_{i} \Longrightarrow-6.005368 \mathrm{E}-06\left[1 /\left(m^{\circ} \mathrm{K}\right)\right]$ \\
\hline$M_{z}^{2} \Longrightarrow+1.175272 \mathrm{E}-07\left[1 /\left(N m^{2}\right)\right]$ & \\
\hline
\end{tabular}

iteration equation. The coefficients of $W_{1}, W_{2}, \ldots, \Delta T_{d}$ in Table 6 above are the coefficient subset of matrix $\mathbf{C}_{\mathbf{1}}^{-1}$ that is used to predict the axial force. Similarly, the coefficients of $F_{x}^{2}, \ldots, M_{z} \cdot \Delta T_{i}$ are the coefficient subset of matrix $\mathbf{C}_{\mathbf{1}}^{-\mathbf{1}} \mathbf{C}_{\mathbf{2}}$ that is needed to predict the axial force.

It is expected, after reviewing conclusions given in Ref. [1], that the data reduction matrix coefficient of the cross-product term constructed from the axial force and the temperature difference, i.e., $F_{x} \cdot \Delta T_{i}$, must be related to the temperature-dependent sensitivity shift of the axial force gage. Furthermore, the contribution of the cross-product term $F_{x} \cdot \Delta T_{i}$ of the data reduction matrix to the axial force at load capacity of $4000 \mathrm{~N}$ and balance temperature $315^{\circ} \mathrm{K}$ (i.e., $\Delta T_{i}=21^{\circ} \mathrm{K}$ ) can be obtained by simply multiplying the negative of the data reduction matrix coefficient $\xi$ with the corresponding values for $F_{x}$ and $\Delta T_{i}$. The negative of 
the coefficient must be used in this context because the load iteration equation subtracts contributions of higher order terms (see also the definition of the Iterative Method's load iteration equation that is given in Refs. [1] and [2]). Then, we get the following value for the load contribution that can be attributed to the temperature-dependent sensitivity shift of the axial force gage:

$$
\begin{aligned}
\delta F_{x} & \approx(-1) \cdot \xi \cdot\left\{F_{x} \cdot \Delta T_{i}\right\} \\
& \approx(-1) \cdot \underbrace{+2.452692 \cdot 10^{-4}\left[1 /{ }^{\circ} K\right]}_{\xi, \text { taken from Table } 6} \cdot \underbrace{4000[N]}_{F_{x}} \cdot \underbrace{(315-294)\left[{ }^{\circ} K\right]}_{\Delta T_{i}} \\
& \approx-20.60[N]
\end{aligned}
$$

It is concluded that the sensitivity change is responsible for an axial force difference of about $-21[N]$ if (i) the axial force $F_{x}$ is $4000[N]$ and (ii) the temperature difference $\Delta T_{i}$ equals $21^{\circ} \mathrm{K}$. This "theoretical" estimate can be related to the "observed" residuals that are shown in Fig. $7 \mathrm{~b}$. In that case, the simple omission of the modeling of temperature effects caused a difference of about $-0.5 \%$ of capacity at $100 \%$ axial force. These values result in an error of $-0.005 \times 4000[N]$ or $-20[N]$ which agrees well with the "theoretical" estimate that is given in Eq. (6) above.

\section{Non-Iterative Method}

It is also possible to use the Non-Iterative Method for the analysis of the temperature-dependent calibration data of RUAG's 788-6A balance. This alternate method is much simpler to implement than the Iterative Method. Suitable regression models of the six load components, i.e., $F_{x}, \ldots, M_{z}$, of the $788-6 \mathrm{~A}$ balance can be defined using the transformed outputs, i.e., $W_{1}, \ldots, W_{6}$, and the temperature difference.

First, similar to the application of the Iterative Method to the data, only data at $294^{\circ} \mathrm{K}$ was analyzed. This data consisted of 406 points. Table 7 below shows regression model terms of the six load components of the balance that were used for this part of the analysis. Again, as it was the case during application of the Iterative Method, only seven of fifteen possible cross-product terms are used because the remaining eight output combinations were either not explicitly applied during the calibration or related output magnitudes were too small. No temperature-dependent terms are required as all data points were recorded at $294^{\circ} \mathrm{K}$.

Table 7: Supported regression model terms of the balance loads that were applied at $294^{\circ} \mathrm{K}$.

\begin{tabular}{|c|c|}
\hline Type & Non-Iterative Method $\Longrightarrow$ List of Regression Model Terms for $F_{x}, F_{y}, \ldots, M_{z}$ \\
\hline \hline constant (1) & Intercept \\
\hline linear $(6)$ & $W_{1}, W_{2}, W_{3}, W_{4}, W_{5}, W_{6}$ \\
\hline quadratic $(6)$ & $W_{1}^{2}, W_{2}^{2}, W_{3}^{2}, W_{4}^{2}, W_{5}^{2}, W_{6}^{2}$ \\
\hline cross-product $(7)$ & $\left(W_{1} \cdot W_{6}\right),\left(W_{2} \cdot W_{4}\right),\left(W_{2} \cdot W_{6}\right),\left(W_{3} \cdot W_{4}\right),\left(W_{3} \cdot W_{5}\right),\left(W_{4} \cdot W_{5}\right),\left(W_{4} \cdot W_{6}\right)$ \\
\hline
\end{tabular}

A total of twenty regression model terms for each load component were supported by the calibration data. The terms are indirectly related to similar terms that are shown in Table 4 for the Iterative Method. They are simply the result of the fact that the six transformed outputs are approximately proportional to the corresponding six balance loads (see also Eqs. $(1 a)$ to $(1 f)$ ). Then, the regression model of the axial force at constant temperature can be defined as follows:

$$
\begin{aligned}
F_{x}=b_{\circ} & +\underbrace{b_{1} \cdot W_{1}+b_{2} \cdot W_{2}+\ldots+b_{6} \cdot W_{6}}_{\text {linear terms }}+\underbrace{b_{7} \cdot W_{1}^{2}+b_{8} \cdot W_{2}^{2}+\ldots+b_{12} \cdot W_{6}^{2}}_{\text {cross-product terms }} \\
& +\underbrace{b_{13} \cdot W_{1} \cdot W_{6}+b_{14} \cdot W_{2} \cdot W_{4}+\ldots+b_{19} \cdot W_{4} \cdot W_{6}}_{\text {quadratic terms }}
\end{aligned}
$$


Regression models of the other five load components have a similar structure. Now, the BALFIT software was used to determine the regression coefficients $b_{\circ}, \ldots, b_{19}$ that the Non-Iterative Method needs for the prediction of the axial force during a wind tunnel test. Figure 9a below shows the corresponding residuals of the axial force for the calibration data that was recorded at $294^{\circ} \mathrm{K}$.

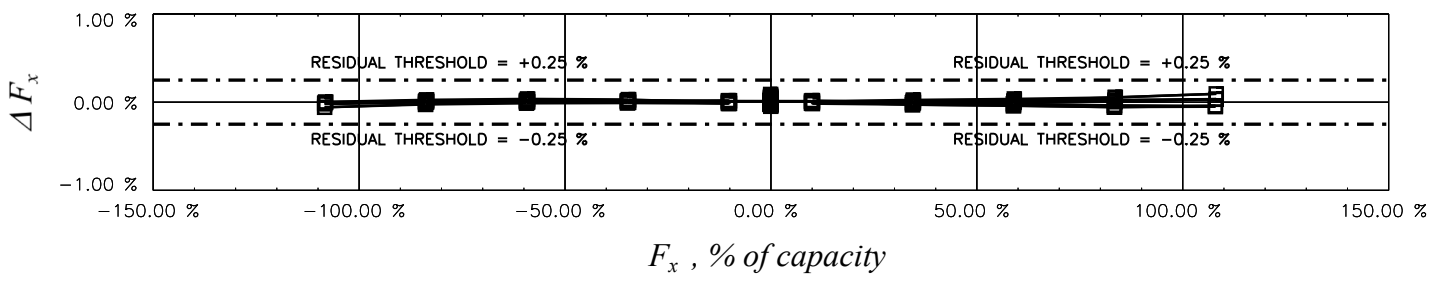

Fig. 9a Non-Iterative Method $\Longrightarrow$ Calibration load residuals of the axial force for data recorded at $294^{\circ} \mathrm{K}$.

Overall, results of the load prediction are very good. The residuals of all 406 data points are within the $\pm 0.25 \%$ threshold that is used in aerospace testing for the assessment of balance load residuals. In the next step, the above regression model of the axial force was applied to the 38 check load points that were recorded at $315^{\circ} \mathrm{K}$. Figure $9 \mathrm{~b}$ below shows resulting check load residuals of the axial force plotted versus the tare corrected axial force of each check load point.

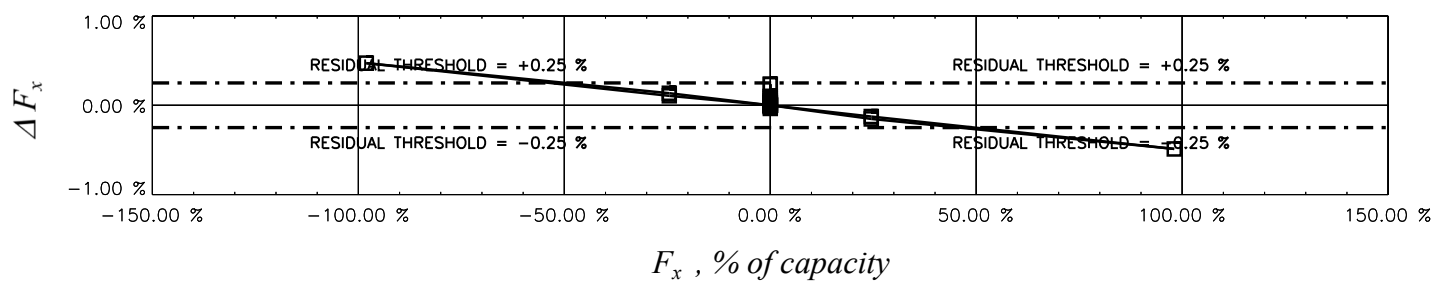

Fig. 9b Non-Iterative Method $\Longrightarrow$ Check load residuals of the axial force if the regression model obtained from the data at $294^{\circ} \mathrm{K}$ is used to process the outputs that were recorded at $315^{\circ} \mathrm{K}$.

Again, similar to results plotted in Fig. 7b, an unwanted "slope" is visible in the check load residual plot. This observation indicates that the primary gage sensitivities of the balance changed when the balance was heated to $315^{\circ} \mathrm{K}$. The regression model obtained exclusively from the $294^{\circ} \mathrm{K}$ data cannot correctly process outputs at the elevated balance temperature of $315^{\circ} \mathrm{K}$. Therefore, it will be necessary to use the Non-Iterative Method for the analysis of the combined calibration data that was recorded at $294^{\circ} \mathrm{K}$ and $315^{\circ} \mathrm{K}$ so that the temperature-dependent characteristics of the balance are included in the load prediction.

Now, in order to obtain a temperature-dependent regression model of the axial force for the processing of the check load data at $315^{\circ} \mathrm{K}$, the Non-Iterative Method was applied to the combined calibration data consisting of (i) the 406 data points at $294^{\circ} \mathrm{K}$ and (ii) the 54 data points at $315^{\circ} \mathrm{K}$. Table 8 below shows the regression model terms of the axial force that were constructed from (i) the six transformed gage outputs and (ii) the temperature difference (these terms were also used to analyze the remaining five load components).

Table 8: Supported regression model terms of the balance loads that were applied at $294^{\circ} \mathrm{K} \& 315^{\circ} \mathrm{K}$.

\begin{tabular}{|c|c|}
\hline Type & Non-Iterative Method $\Longrightarrow$ List of Regression Model Terms for $F_{x}, F_{y}, \ldots, M_{z}$ \\
\hline \hline constant (1) & Intercept \\
\hline linear (6) & $W_{1}, W_{2}, W_{3}, W_{4}, W_{5}, W_{6}$ \\
\hline quadratic (6) & $W_{1}^{2}, W_{2}^{2}, W_{3}^{2}, W_{4}^{2}, W_{5}^{2}, W_{6}^{2}$ \\
\hline cross-product $(7)$ & $\left(W_{1} \cdot W_{6}\right),\left(W_{2} \cdot W_{4}\right),\left(W_{2} \cdot W_{6}\right),\left(W_{3} \cdot W_{4}\right),\left(W_{3} \cdot W_{5}\right),\left(W_{4} \cdot W_{5}\right),\left(W_{4} \cdot W_{6}\right)$ \\
\hline temperature $(7)$ & $\Delta T_{i},\left(W_{1} \cdot \Delta T_{i}\right),\left(W_{2} \cdot \Delta T_{i}\right),\left(W_{3} \cdot \Delta T_{i}\right),\left(W_{4} \cdot \Delta T_{i}\right),\left(W_{5} \cdot \Delta T_{i}\right),\left(W_{6} \cdot \Delta T_{i}\right)$ \\
\hline
\end{tabular}


A total of 27 regression model terms for each load component were supported by the temperaturedependent calibration data (intercept, seven linear terms, six quadratic terms, and thirteen cross-product terms). The resulting regression model of the axial force can be defined as follows:

$$
\begin{aligned}
F_{x}=b_{\circ} & +\underbrace{b_{1} \cdot W_{1}+\ldots+b_{6} \cdot W_{6}+b_{7} \cdot \Delta T_{i}}_{\text {linear terms }}+\underbrace{b_{8} \cdot W_{1}^{2}+\ldots+b_{13} \cdot W_{6}^{2}}_{\text {quadratic terms }} \\
& +\underbrace{b_{14} \cdot W_{1} \cdot W_{6}+b_{15} \cdot W_{2} \cdot W_{4}+\ldots+b_{20} \cdot W_{4} \cdot W_{6}}_{\text {cross-product terms }} \\
& +\underbrace{b_{21} \cdot W_{1} \cdot \Delta T_{i}+b_{22} \cdot W_{2} \cdot \Delta T_{i}+\ldots+b_{62} \cdot \Delta T_{i}}_{\text {temperature-dependent cross-product terms }}
\end{aligned}
$$

In the next step, the BALFIT software computed the regression coefficients $b_{\circ}$ to $b_{26}$ of the axial force by using the combined calibration data at $294^{\circ} \mathrm{K}$ and $315^{\circ} \mathrm{K}$ as input. Figure 10a below shows resulting residuals of the axial force for the combined calibration data when plotted versus the tare corrected axial force itself.

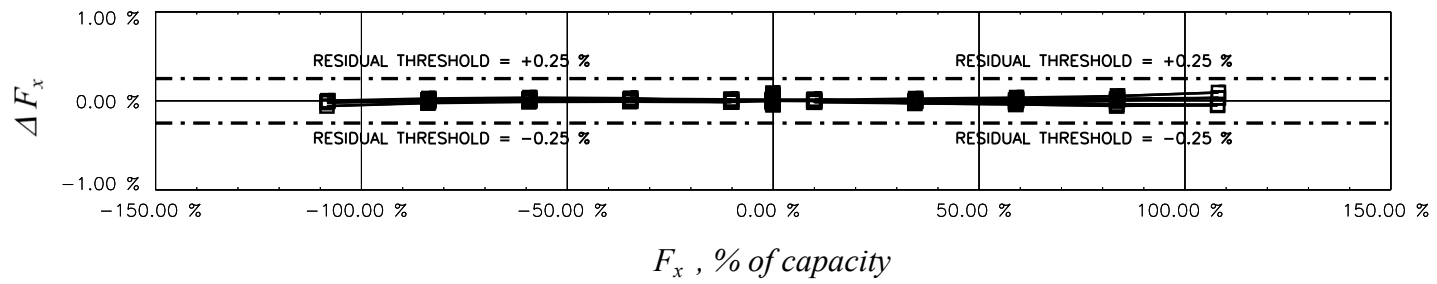

Fig. 10a Non-Iterative Method $\Longrightarrow$ Calibration load residuals of the axial force for the combined data that was recorded at $294^{\circ} \mathrm{K} \& 315^{\circ} \mathrm{K}$.

As expected, the results of the load prediction for the combined calibration data are very good. All load residuals are within the $\pm 0.25 \%$ threshold. Finally, the regression model of the axial force obtained from the combined calibration data was applied to the 38 check load points that were recorded at $315^{\circ} \mathrm{K}$. Figure 10b shows the resulting check load residuals of the axial force data recorded at $315^{\circ} \mathrm{K}$ when plotted versus the tare corrected axial force.

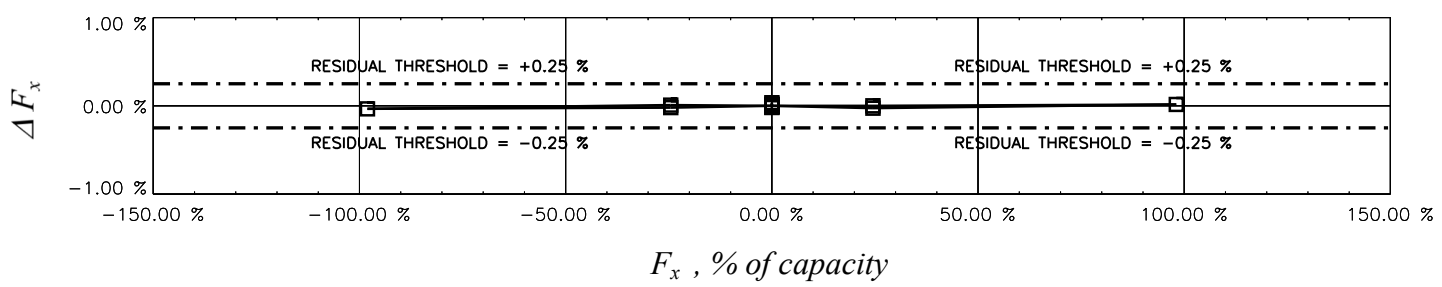

Fig. 10b Non-Iterative Method $\Longrightarrow$ Check load residuals of the axial force if the regression model obtained from the data at $294^{\circ} \mathrm{K} \& 315^{\circ} \mathrm{K}$ is used to process outputs that were recorded at $315^{\circ} \mathrm{K}$.

Now, the prediction of the check load data at $315^{\circ} \mathrm{K}$ meets accuracy requirements as (i) the residuals of all 38 check load points are well within the $\pm 0.25 \%$ threshold and (ii) the "slope" seen earlier in Fig. 9b has disappeared.

Contributions of the individual regression model terms of the axial force for the combined calibration data are investigated in more detail in order to identify the term that is primarily responsible for the correct characterization of the temperature-dependent nature of the gage sensitivity. Table 9 below lists the 27 coefficients of the regression model of the axial force.

American Institute of Aeronautics and Astronautics 
Table 9: Regression coefficients of the axial force.

\begin{tabular}{|c|c|}
\hline Math Term $\Longrightarrow$ Coefficient, Unit & Math Term $\Longrightarrow$ Coefficient, Unit \\
\hline \hline Intercept $\Longrightarrow+\mathbf{8 . 8 0 0 0 3 2} \mathrm{E}+\mathbf{0 1}[N]$ & $W_{1} \cdot W_{6} \Longrightarrow+2.204092 \mathrm{E}-06\left[N /(\mu V / V)^{2}\right]$ \\
\hline$W_{1} \Longrightarrow+\mathbf{2 . 1 4 9 1 4 4} \mathrm{E}+\mathbf{0 0}[N /(\mu V / V)]$ & $W_{2} \cdot W_{4} \Longrightarrow-1.253588 \mathrm{E}-08\left[N /(\mu V / V)^{2}\right]$ \\
\hline$W_{2} \Longrightarrow+3.143109 \mathrm{E}-03[N /(\mu V / V)]$ & $W_{2} \cdot W_{6} \Longrightarrow+5.205588 \mathrm{E}-07\left[N /(\mu V / V)^{2}\right]$ \\
\hline$W_{3} \Longrightarrow-5.268953 \mathrm{E}-04[N /(\mu V / V)]$ & $W_{3} \cdot W_{4} \Longrightarrow-5.279539 \mathrm{E}-08\left[N /(\mu V / V)^{2}\right]$ \\
\hline$W_{4} \Longrightarrow-2.623613 \mathrm{E}-06[N /(\mu V / V)]$ & $W_{3} \cdot W_{5} \Longrightarrow-1.380827 \mathrm{E}-06\left[N /(\mu V / V)^{2}\right]$ \\
\hline$W_{5} \Longrightarrow+6.588438 \mathrm{E}-03[N /(\mu V / V)]$ & $W_{4} \cdot W_{5} \Longrightarrow+6.563246 \mathrm{E}-08\left[N /(\mu V / V)^{2}\right]$ \\
\hline$W_{6} \Longrightarrow+1.114731 \mathrm{E}-03[N /(\mu V / V)]$ & $W_{4} \cdot W_{6} \Longrightarrow+1.050742 \mathrm{E}-06\left[N /(\mu V / V)^{2}\right]$ \\
\hline$\Delta T_{i} \Longrightarrow-3.700731 \mathrm{E}-02\left[N /{ }^{\circ} K\right]$ & $W_{1} \cdot \Delta T_{i} \Longrightarrow-\mathbf{5 . 2 4 6 7 6 2} \mathrm{E}-\mathbf{0 4}\left[N /\left({ }^{\circ} K \mu V / V\right)\right]$ \\
\hline$W_{1}^{2} \Longrightarrow+3.069670 \mathrm{E}-07\left[N /(\mu V / V)^{2}\right]$ & $W_{2} \cdot \Delta T_{i} \Longrightarrow-8.196839 \mathrm{E}-05\left[N /\left({ }^{\circ} \mathrm{K} \mu V / V\right)\right]$ \\
\hline$W_{2}^{2} \Longrightarrow+2.987536 \mathrm{E}-08\left[N /(\mu V / V)^{2}\right]$ & $W_{3} \cdot \Delta T_{i} \Longrightarrow-1.997981 \mathrm{E}-04\left[N /\left({ }^{\circ} \mathrm{K} \mu V / V\right)\right]$ \\
\hline$W_{3}^{2} \Longrightarrow-2.338164 \mathrm{E}-07\left[N /(\mu V / V)^{2}\right]$ & $W_{4} \cdot \Delta T_{i} \Longrightarrow-1.391534 \mathrm{E}-05\left[N /\left({ }^{\circ} \mathrm{K} \mu V / V\right)\right]$ \\
\hline$W_{4}^{2} \Longrightarrow-1.730824 \mathrm{E}-09\left[N /(\mu V / V)^{2}\right]$ & $W_{5} \cdot \Delta T_{i} \Longrightarrow+1.639202 \mathrm{E}-05\left[N /\left({ }^{\circ} \mathrm{K} \mu V / V\right)\right]$ \\
\hline$W_{5}^{2} \Longrightarrow+3.396603 \mathrm{E}-09\left[N /(\mu V / V)^{2}\right]$ & $W_{6} \cdot \Delta T_{i} \Longrightarrow+1.486527 \mathrm{E}-06\left[N /\left({ }^{\circ} \mathrm{K} \mu V / V\right)\right]$ \\
\hline$W_{6}^{2} \Longrightarrow-4.025278 \mathrm{E}-09\left[N /(\mu V / V)^{2}\right]$ & - \\
\hline
\end{tabular}

The contribution of the cross-product term $W_{1} \cdot \Delta T_{i}$ is expected to be the dominant temperaturedependent term as the output $W_{1}$ is approximately proportional to the axial force $F_{x}$. An estimate of the gage output $W_{1}$ at load capacity is needed so that the related temperature-dependent cross-product term can be evaluated. This estimate can indirectly be obtained by truncating the regression model of the axial force, i.e., Eq. (8), after the second term. Then, we get:

$$
F_{x} \approx b_{\circ}+b_{1} \cdot W_{1}
$$

Now, after some algebra, the following estimate of the transformed output is obtained:

$$
W_{1}\left(F_{x}\right) \approx \frac{F_{x}-b_{\circ}}{b_{1}}
$$

Values on the right-hand side of Eq. (9b) above are either known or can be obtained from Table 9. Then, assuming that the output at axial force capacity, i.e., at $F_{x}=4000[N]$, is to be computed, we get:

$$
W_{1} \approx \frac{\overbrace{4000[N]}^{F_{x}}-\overbrace{8.800032 \cdot 10^{+1}[N]}^{b_{\circ} \text {, taken from Table } 9}}{\underbrace{+2.149144[N /(\mu V / V)]}_{b_{1}, \text { taken from Table } 9}} \approx 1820[\mu \mathrm{V} / \mathrm{V}]
$$

Finally, the contribution of the temperature-dependent cross-product term $W_{1} \cdot \Delta T_{i}$ to the axial force can be estimate. We get:

$$
\begin{aligned}
\delta F_{x} & \approx b_{21} \cdot\left\{W_{1} \cdot \Delta T_{i}\right\} \\
& \approx \underbrace{\left(-5.246762 \cdot 10^{-4}\right)\left[N /\left({ }^{\circ} K \mu V / V\right)\right]}_{b_{21}, \text { taken from Table } 9} \cdot \underbrace{1820[\mu V / V]}_{E q .(9 c)} \cdot \underbrace{21\left[{ }^{\circ} K\right]}_{\Delta T_{i}} \\
& \approx-20.05[N]
\end{aligned}
$$


It is concluded that the temperature-dependent gage sensitivity change is responsible for an axial force prediction difference of $-20.05[N]$ if the axial force equals $4000[N]$ and the temperature difference equals $21^{\circ} \mathrm{K}$. This theoretical estimate is in good agreement with the corresponding value of $-20.60[N]$ that was obtained after the application of the Iterative Method to the combined calibration data (see Eq. (6)). Therefore, it is concluded that the cross-product term constructed from (i) the axial gage output $W_{1}$ and (ii) the temperature difference $\Delta T_{i}$ quantifies the contribution of the temperature-dependent gage sensitivity shift during the prediction of the axial force if the Non-Iterative Method is used for the load prediction.

\section{Summary and Conclusions}

Temperature-dependent calibration data of a RUAG six-component block-type balance was analyzed using two different balance load prediction methods. The first method is a recently developed variation of the Iterative Method. In that case, balance outputs are fitted as a function of the loads and the temperature difference. Afterwards, a load iteration scheme is constructed from the regression coefficients so that loads can be predicted from the measured outputs during a wind tunnel test. The second method is the NonIterative Method. This approach is more easily applied to balance data because loads are directly fitted as a function of the electrical outputs of the balance bridges and the temperature difference.

Overall, analysis results from both methods lead to similar conclusions. First, it was demonstrated using the given balance calibration data and a set of independent check loads that the temperature-dependent nature of the sensitivity of a balance gage can be quantified by a cross-product term in the regression model of the data that is constructed from (i) the primary gage load and (ii) the temperature difference if the Iterative Method is used for the load prediction. Similarly, using the same data, it was demonstrated that the temperature-dependent nature of the sensitivity of a balance gage can also be quantified by a crossproduct term in the regression model of the data that is constructed from (i) the primary gage output and (ii) the temperature difference if the Non-Iterative Method is applied.

It could also be illustrated that temperature-dependent load predictions for the Iterative Method are as good as corresponding results for the Non-Iterative Method as long as the chosen regression models (i) are supported by the calibration data and (ii) do not have any linear or near-linear dependencies. However, it must not be overlooked that the Non-Iterative Method is much easier to implement in a wind tunnel data system than the Iterative Method. Therefore, it may be the better choice when it comes to developing and deploying a temperature-dependent load prediction process for a strain-gage balance in a wind tunnel facility.

\section{Acknowledgements}

The authors want to thank Bob Gisler and Jon Bader of NASA for their critical and constructive review of the final manuscript. The work reported in this paper was partially supported by the Wind Tunnel Division at NASA Ames Research Center under contract NNA16BD26C.

\section{References}

[1] Ulbrich, N., and Volden, T., "Regression Analysis and Calibration Recommendations for the Characterization of Balance Temperature Effects," paper presented at the 11th International Symposium on Strain-Gauge Balances, Cologne, Germany, May 2018.

[2] AIAA/GTTC Internal Balance Technology Working Group, Recommended Practice, Calibration and Use of Internal Strain-Gage Balances with Application to Wind Tunnel Testing, AIAA R-091-2003, American Institute of Aeronautics and Astronautics, Reston, Virginia, 2003.

[3] Ulbrich, N., "Comparison of Iterative and Non-Iterative Strain-Gage Balance Load Calculation Methods," AIAA 2010-4202, paper presented at the 27th AIAA Aerodynamic Measurement Technology and Ground Testing Conference, Chicago, Illinois, June/July 2010.

[4] Ulbrich, N., "Regression Model Optimization for the Analysis of Experimental Data," AIAA 2009-1344, paper presented at the 47th AIAA Aerospace Sciences Meeting, Orlando, Florida, January 2009. 
[5] Zimmermann, C., Häberli, W., and Monkewitz, M., "Precise Measurement Technology Based on new Block-type and Rotating Shaft Balances," AIAA 2010-4541, paper presented at the 27th AIAA Aerodynamic Measurement Technology and Ground Testing Conference, Chicago, Illinois, June/July 2010.

[6] Kloetzli, L., and Zimmermann, C., "Statistic Criteria to improve the non-linear Balance Matrix Evaluation," paper presented at the 11th International Symposium on Strain-Gauge Balances, Cologne, Germany, May 2018.

[7] Ulbrich, N., "Assessment of the Uniqueness of Strain-Gage Balance Load Predictions," AIAA 20164157, paper presented at the 32nd AIAA Aerodynamic Measurement Technology and Ground Testing Conference, Washington, D.C., June 2016.

[8] ASC/ENSI, Metallic Materials and Elements for Aerospace Vehicle Structures, Military Handbook, MIL-HDBK-5H, Wright-Patterson AFB, Ohio, 1998, p. 2-197.

[9] International Organization of Legal Metrology (OIML), International Recommendation OIML $R$ 111-1 Edition $2004(E)$, weights of classes $\mathrm{E}_{1}, \ldots$, and $\mathrm{M}_{3}$, Part 1: Metrological and technical requirements, Bureau International de Métrologie Légale, Paris, 2004.

[10] Ulbrich, N., and Volden, T., BALFIT - Software Tool for the Regression Analysis of Multivariate Data, User Guide (revised and corrected 4th edition), Jacobs Technology Inc., prepared for NASA Ames Research Center under contract NNA09DB39C, February 2016. 